\title{
Exploring Teachers' Perceptions on Organizational Climate in Urban and Rural Schools
}

\author{
Edit Lezha, (PhD C.) \\ Faculty of Educational Sciences, \\ University of Shkoder "Luigj Gurakuqi”, Albania
}

doi: 10.19044/esj.2017.v13n13p402 URL:http://dx.doi.org/10.19044/esj.2017.v13n13p402

\begin{abstract}
The aim of this research was to understand how teachers who work at urban and rural high schools perceive their school climate in terms of their professional development. A qualitative research design was carried out to collect data with a group of 24 teachers who were selected based on their participation in postgraduate degree courses for professional development offered by the faculty of Educational Sciences at University of Shkoder. Many studies on school effectiveness emphasize the importance of organizational climate in which effective teaching and learning occur. Several factors have a crucial role in defining a successful school climate but three organizational climate factors were chosen for this study; collegial support, teachers' autonomy and principal role. Also, this paper attempted to offer some kind of an alternative for assessing the school climate in order to review teacher's training plan for professional development.
\end{abstract}

Keywords: Organizational climate, teacher, professional development, training plan.

\section{Introduction}

Professional development programs are systematic efforts to bring about change in the classroom practices of teachers, in their attitudes and beliefs, and in the learning outcome of students.” (Guskey,2002,p.381). Four principles of effective professional development (Guskey, 2000) are:

(a) A clear focus on learning and learners;

(b) An emphasis on individual and organizational change;

(c) Small changes guided by a grand vision; and (d) ongoing professional development that is procedurally embedded.

One of the issues related to emphasis on individual and organizational change is related to school climate evaluation. School climate, in particular, is defined as "the relatively enduring quality of the 
school environment that is experienced by participants, affects their behavior, and is based on their collective perception of behavior in schools" (Hoy \& Tarter, 1997, p. 6). The perception of a positive school climate can be described as an agreeable relationship among everybody in the school (Van Horn, 2003) where each person in the school interacts in informal ways that help build the school (Witcher, 1993). According to Hoy \& Miskel (1991, p.221): School climate is a broad term that refers to teachers' perceptions of the general work environment of the school; it is influenced by the formal organization, informal organization, personalities of participants, and organizational leadership. The climate of a school may roughly be conceived as the personality of a school; that is, personality is to individual as climate is to organization.

Assessing the school climate mirrors the interaction patterns in a school. It is a foundation for self-analysis and organizational improvement. As Deer (1980, p.41) points out: Once organizational climate is assessed, however, there are so far no tried and tested ways of changing that climate. Yet awareness of the perceptions of others is important feedback for all concerned. It provides a foundation for a school to review variables affecting its organizational climate. Such a review can lead to revisions of school policy and thus improving the quality of life for all concerned.

Many theories emphasize the importance of several factors role in defining a successful school climate but three organizational climate factors were selected for this study; collegial support, teachers“ autonomy and principal role.

Collegial support is important in collaborative schools. Collegial relationships exist when teachers discuss problems and difficulties, share ideas and knowledge, exchange techniques and approaches, observe one another's work, and collaborate on instructional projects (Little, 1982; Rosenholtz, 1989; Smylie, 1988). In schools where collegiality is the norm, these professional, interactive, supportive relationships are accepted, enhanced, and socially encouraged (Little, 1982). Such relationships have a key impact on schools and provide the opportunity for teachers to work together on improvement activities.

A positive learning and teaching environment is essential if students are to succeed in school. Research shows that there is a direct link between students' success and the school environment in which learning takes place. Students are more motivated to do well and to realize their full potential in schools that have a positive school climate, where they feel safe and supported (Safe Schools Action Team, Shaping a Culture of Respect in Our Schools: Promoting Safe and Healthy Relationships, 2008, p. 1).

Teacher autonomy can be defined as the level of control that teachers perceive they have over their instruction and their environment. 
Hinchey, P. H. (1998) suggests that empowerment stems from content knowledge, classroom guardianship, and administrative and collegial support. Thompson (1996) pointed out, "Where a team and collegial environment does not exist, the principal is the logical person to initiate the movement toward such an environment” (p. 34). The main principal role is facilitating the school climate and is held to the responsibility of making that climate successful in meeting the needs of its teachers and students (Kelley et al., 2005). When teachers feel the school leadership supports them, they take risks that are more creative in their delivery of teaching and learning. Thompson (1996) added, "Supportive principals are in tune to the needs of teachers and are there to offer the support necessary for teachers to meet their challenges" (p. 150).

The aim of this research was to explore and compare how teachers who work at urban and rural high schools perceive their school climate in terms of their professional development.

Two research questions derived from the purpose of the study:

1. How teachers perceive collegial support, autonomy and principal role in their work environment?

1. How teachers' perception on school climate differs from urban school teachers and rural ones?

\section{Methodology}

This section includes a brief description of the participants, the data collection technique, the data collection procedures and the data analysis procedures of the study. A qualitative research design was carried out to collect data with a group of 24 teachers from urban and rural high schools that were selected based on their participation in postgraduate degree courses for professional development offered by the faculty of Educational Sciences at University of Shkoder. This purposive sample is based on deliberate conscious effort by the researchers to select beneficiaries who meet the criteria for research and they are selected because of their experience or opinions on the topic of research. Participants are selected on the basis of characteristics or experiences that are directly related to the area of interest to researchers and their research questions, allow researchers to study the subject in depth. Selected cases are those that can discover and throw as much light on the field of study. (Matthews \& Ross, 1998).

\subsection{Data Collection}

The duration of the interviews ranged from 30- 40 minutes were structured and tailored around phenomenological interview Seidman Model (Seidman (1998, p.11) shows that any qualitative research is based on data from the interview should include more than a single interview. The first 
interview is the story of life, and participants are asked to separate as much as possible at the time the interview. Preparation of semi-structured questions was based in order to collect as much information possible from second interview. The interview focuses on the extraction of details of lived experiences based on four organizational climate factors (organizational structure, collegial support, student support, autonomy and principal influence).

\subsection{Data analysis}

The process of data collection continued until it reached "saturation data”. This closing point is reached when the information provided by participants made repeated and contains no new ideas (http://www.encyclo.co.uk/define/ Date\% 20saturation).

Data were coded and organized after some interpretive steps to ensure that their no sense not to miss. A theme is given for each subcategory corresponding to the sense of coding. Codes of sub-categories are constantly checked and compared with data collected to verify the meaning and common themes reflected in interviews (Bowen 2008). Formation of sub-category and category was not formed by numerical frequency units, but more in the sense of described meanings and connections found in interviews.

\section{Results}

What really helped in giving a consoled interpretation of the difference level perception of teachers was the interview codification. From the semi structured interview teachers from urban school declared that the prominent factors surrounding job satisfaction among teachers in urban schools are not the same as those found in rural schools. Derlin and Schneider (1994) reported that job dissatisfaction in both school types consists of three primary factors. In suburban schools the factors are extrinsic: pay, advancement and job security. Conversely, in urban schools the factors are intrinsic in nature: recognition and involvement in decision making and support. In addition to instructional support and support with student discipline issues, support is also needed by most teachers in urban schools regarding cultural diversity (Bradley \& Loadman, 2005; Hill \& Gillette, 2005; NG, 2003; Rushton, 2001).

Teachers from urban schools in this study made the following recommendations for principals based on their experiences and what they desire in a school leader. They were divided in three main groups' statements:

1. Communication must be consistent and thorough

2. Include teachers in the decision-making 
3. Recognize teachers' efforts

For rural teachers

1. being visible during the day so that the students see you taking an active role in their learning.

2. being ready to do any task that you expect the teachers to do

3. Communication must be consistent and thorough

Also, teachers from both urban and rural schools were on the same line for organizational structure emphasizing that there is a slightly difference between urban and rural areas. Even the chart of public schools is the same in both areas the organizational structure is mostly connected to the logistic part and the student and staff support that give in learning process.

Teachers' perception of student support is connected mostly with decreasing enrollment in basic education. According to them in rural areas this is significantly affected by increasing internal and external migration, as well as the few economic opportunities of the inhabitants of these areas.In rural schools, participants talked about closer school-community relations. To be a rural teacher was to be a part of a family community. The rural environment is a place where everyone knows everyone. Because of these close relationships, rural teachers were readily able to identify with the background of students, and parents were more involved with the school. As well, administration was more active in the life of the teacher, and individual teachers were more influential upon the lives of students. The experience and perspectives of an urban teacher were directly related to the larger school enrollments. As urban teachers, participants often taught in a culturally diverse classroom, and felt a greater sense of teaching autonomy. Administration was less active in the lives of the teachers. Professional development was more accessible, and professional collaboration or professional committee memberships were more encompassing and active in urban communitie

\section{Conclusion \& Recommendations}

The school climate, the tone of the school, and the school environment represent the surroundings in which the teachers conduct their practice. Principals must create an environment for teaching and learning. The principal must remain visible to the teachers and students give the structure for the school day, ensure that school policies are enforced, and provide teachers with the many supports (including instructional support beyond induction) and resources needed to do their job effectively. Collegiality is nurtured when administrators provide encouragement and accommodation (Johnson, 1990). While most research points to the ways in which principals have provided leadership and support for improvement 
efforts (Deal and Peterson, 1990; Fullan, 1991). Principals can foster collegiality by promoting teacher leadership and encouraging teachers to exchange ideas and work together. This goal may require the principal to set agendas for meetings and to work on issues close to the classroom. Principals can create a time and place for professional dialogue and team work, provide substitute teachers and cover classes for teachers who wish to participate in collaboration activities, and make similar accommodations for groups of teachers who wish to work together on a project. Above all, fostering collegial relationships requires both time and structured opportunities for joint work. The general teaching autonomy factor is logically consistent with the need for teachers to have control over their work environment, to stay satisfied with the job, and to stay committed to the profession. A measure of teacher autonomy could provide those who hire teachers with the insight to identify those who are satisfied with their jobs and professional identity.

\section{References:}

1. Bowen GA (2008) Naturalistic inquiry and the saturation concept: a research note. Qualitative Research, 8(1), 137-152.

2. Bradley, K. D., \& Loadman, W. E. (2005). Urban secondary educators' views of teacher recruitment and retention. NASSP Bulletin, 89(644), 2-28.

3. Deal, T. \& Peterson, K. (1990). The principal's role in shaping school culture. Washington, D.C.: U.S. Department of Education.

4. Deer, C E (1980): Measuring Organizational Climate in Secondary Schools, in TheAustralian Journal of Education, Vol. 24, No. 1, pp. 26-41.

5. Derlin, R. \& Schneider, g.t. (1994). Urban Education: Understanding Job Satisfaction Principals and Teachers. Urban and Suburban, Vol. 29(1), pp. 63-88.

6. Guskey, T. R. (2002). Professional development and teacher change. Teachers and Teaching:Theory and Practice, 8(3/4), 381-391.

7. Hinchey, P. H. (1998) Finding freedom in the classroom: A practical introduction to critical theory. New York: Peter Lang Publishing.

8. Hinchey, P. H. (1997). Teacher leadership: Introduction. The Clearing House, 70(5), 233-236

9. Hoy, W K \& Miskel, C G (1991): Educational Administration Theory,Research \& Practice (4th ed.), McGraw-Hill

10. Hoy, W. K., \& Tarter, C. J. (1997). The road to open and healthy schools: A handbook for change (Middle and secondary school ed.). Thousand Oaks, CA: CorwinPress. 
11. Johnson, S. M. (1990). Teachers at work: Achieving success in our schools. New York: Basic Books, Inc., Publishers.

12. Kelley, R., Thornton, B., Daugherty, R. (2005). Relationships between measures of leadership and school climate. Education, 126(1), 17-25.

13. Little, J. W. (1982). Norms of collegiality and experimentation: Workplace conditions of school success. American Educational Research Journal, 19(3), 325-340.

14. Oliver, W (2008) The Influence of Principals on Teacher Retention:: A dissertation submitted to the Division of Research and Advance Studies of the University of Cincinnati

15. Seidman I. Interviewing as qualitative research: A guide for the researchers in education \& the social sciences. 4th ed. New York, NY: Teachers College Press; 2013.

16. Thompson, D. P. (1996). Motivating others: Creating the conditions. Princeton, NJ: Eye On Education

17. Van Horn, M. L. (2003). Assessing the unit of measurement for school climate through psychometric and outcome analyses of the school climate survey. Education and Psychological Measurement, 63, 1002-1019.

18. Witcher, A. E. (1993). Assessing school climate: An important step for enhancing school quality. NASSP Bulletin, 77, 1-5. 